\title{
Blogging in ESL class- gender-based attitude of the engineering students
}

\author{
Sahib Khatoon', Muhammad Jafre Zainol Abidin², Quratulain Mirza ${ }^{3}$, Ashfaq Hussain ${ }^{4}$ \\ ${ }_{1,2,4}^{1}$ School of Educational Studies, University Sains Malaysia, Malaysia \\ ${ }^{3}$ English Language Development Center, Mehran University of Engineering and Technology, Pakistan
}

\begin{abstract}
Article Info
Article history:

Received Apr 16, 2020

Revised Sep 18, 2020

Accepted Oct 22, 2020

Keywords:

Blogging

ESL class

Technology-mediated reading

ABSTRACT

Online learning has given a new context to the teaching and learning environment. This virtual environment changes the attitude of students in language learning. This study aimed to look into the difference among the engineering students' attitudes towards blogging in an ESL class in terms of gender and the effect of multimodal features on their reading attitude. The research method adopted in the present study relied on a qualitative approach. Engineering students from computer science engineering from local public engineering university Mehran University of Engineering and Technology Jamshoro (MUET) were taught English under blogging and were interviewed. Respondents' attitude is mainly positive towards blogging. There were very few differences pointed out from their attitude towards blogging.
\end{abstract}

Techno-savvy

This is an open access article under the CC BY-SA license.

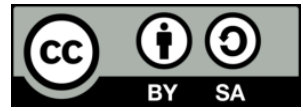

\section{Corresponding Author:}

Sahib Khatoon,

School of Educational Studies,

University Sains Malaysia,

Sungai Dua Road, Gluegor, Penang, Malaysia.

Email: sahib.khatoon@student.usm.my

\section{INTRODUCTION}

Pakistani society is all-gender bias it is not gendered friendly. Women's education especially in rural areas is not common because of norms and customs [1]. Even though the internet is thought to be a worldwide technology people do have differences concerning gender [2]. According to Weiser [3] internet as a technological "boy toy," an automated way of resources of information and entertainment, developed solely by men for men. Similarly, Pakistani society is having such differences in the usage of the internet, social sites, wikis, and blogs, thus those differences lead to the attitude differences too. There are multiple factors which effect on students' attitude towards learning anything, one of them is the gender difference in Pakistan, as girls are not free to use the internet all the time whereas boys have no restrictions.

In Pakistan, there is a gender divide in every sector according to [4], the engineering field is considered as the male dominating field where women ratio is less than men. Moreover, students in engineering universities are studying in many varied disciplines like civil, electrical, mechanical, and industrial, and so on. We can find differences across disciplines as well. For example, civil engineering is the male dominating field whereas software engineering has a good number of female students. Such gender differences cultivate more differences as well, i.e. behavioral, attitude, proficiency, and performance. According to [5] there is a good corpus evident which reveals that women in developing countries are not using ICT as men use that. According to [6] the gender divide is prevailing because of the different factors which can be economical or can be social. These factors hamper and create barriers for females to use technology, in low-income countries, like Pakistan. Therefore, this research is investigating the gender-based 
attitude in blogging class in engineering universities. The continuous concern of policymakers and social scientists is girls/women representation in science, technology, engineering, and mathematics (STEM) fields. It is evident by international databases that this educational-gender-equality paradox is also present in secondary and tertiary education as well [7].

This virtual environment changes the attitude of students in language learning. Moreover [8] stated, assessing the learners' attitude is a must because attitude decides the acceptance and rejection of the technology integration into a particular system. Users' attitudes are an integral indicator of technology integration. The users of technology are male and female both, and their handling of technology is different from each other so their attitude towards technology may be varied from each other too.

Similarly, [9] stated, the relation of L2 acquisition with gender is very well documented in different researches which indicates that male students' performance and interest are lower than female students in L2 language acquisition. The attitude of female ESL students can be different from the male ESL students while attending the English language class which is technology-based as weblog mediated class.

Lee and Pulido [10] stated, that there is a difference in male and female students' way of learning, and performance, the male is not that much interested in reading activities and they spend less time on them, whereas girls likely to spend much time on reading activities. Thus, this research has investigated the male and female students' attitudes towards weblog mediated ESL class specifically reading class.

\section{LITERATURE REVIEW}

Attitude is formed by a set of needs and environmental factors and is assessed complex structure which has many other subcomponents. The strength and durability of an attitude depend on its principal type, which might be effective, behavioral, or cognitive. Cognitively based attitudes are the hardest and strongest to change [11].

The researcher [12] explored, students' target language context and students' contexts matter a lot in developing learners' attitudes towards learning a language, which is a learner's belief about those contexts. Besides [13] postulated, the new environment always needs a user's positive attitude to make his intentions to use that particular thing. Therefore, attitude is providing a context to understand the learner's intentions to use and accept the context, as technology usage in learning a language.

Using technology in a language class is also depends upon its acceptance and proper use according to its need and context. Ardies, et al. [14] argued, that any educational technology can be positively and properly used, when the user knows its practicality and when the user has a positive attitude to use that technology. Without having a positive attitude towards the usage of that technology one cannot attain the real results of that technology integration.

There are numerous researches conducted on learners' attitude towards technology integration into a language class. Jan [15] conducted the study in Pakistani secondary school to know the attitude towards technology in an ESL class. This study shows different demographic factors like age, gender, proficiency in English, training in using computers, access to the internet, usage of hand-held technological devices, and level of computer are positively effecting students' attitudes towards digital literacy.

As Pattanapichet [16] researched to explore the impact of the digital game "Kahoot" on students' learning performance and their motivation towards learning. The research was conducted with two groups one was experimental which was taught by game and another control group with the conventional method. Results revealed differences in the motivation and performances of the students who learned through the game than the control group. The survey also revealed that students had a highly positive attitude towards learning language through the game application.

Another research was conducted by [17] in Oman and UAE by conducting two survey questionnaires with educators and students to explore their attitude towards M-learning in a language class. Results revealed a positive attitude of educators and students towards the M- learning environment. The researcher stated that Attitude towards technology usage is a significant factor to decide whether or not learners and educators ready to use that technology. Such an attitude will further identify the pros and cons of the technology and its facilitation accordingly.

Another study was conducted in Yemen by designing a Computer-Assisted Reading Yemen (CAREY) program and explored whether or not it affects the Yemeni ESL students' reading attitude towards reading English materials. These research findings revealed positive results that showed that students have positive attitudes towards reading English materials which were with different online features and those features like dictionaries, hints, clues about reading texts improve their positive attitudes from the beginning of the experiment until the end [18].

One more research was conducted in Saudi Arabia on female students by [19] for exploring the effects of Edmodo one of the social media tools in language learning to find out Saudi female students' 
attitudes towards ESL learning. Results revealed a positive attitude of students to use Edmodo in learning a language. Edmodo created an online environment that becomes an effective factor to generate a positive attitude, increased confidence, and motivation towards learning the language of Saudi students.

Multiple factors affect attitude and attitude become positive or negative. Similarly, the attitude itself affects the behavior or action. Researches showed those learners who have good reading attitudes are good at reading skills and more competent in reading comprehension as well [20]. The research was conducted in Chulalong Korn University, Bangkok on effects of attitude on learner's reading achievement and the results revealed; there is a great influence of attitude on student's reading achievement, attitudes effect on reading skill, and reading behavior too [21].

Another study was conducted on pre-intermediate level Turkish EFL learners' attitudes towards reading in English. There were pre and post questionnaires administered regarding the "Attitudes towards Reading in English". The results revealed that students neither like nor hate reading in English. The researcher stated it may be because of the influence of the first language which causes poor reading habits in the second language [22].

As Grabe and Stoller [23] also agreed on the argument that poor attitude towards first language reading experiences may influence second language reading. Moreover, the research was conducted in UiTM Sarawak with 98 students to find out the influence of the environment on students' attitudes. Results revealed there is a positive correlation between students' attitudes and the environment with average hours given to them at home and the institution [24]. All the above-mentioned researches are mostly showing positive effects on attitudes by using technology in the ESL class and showed positive results of the students' performances of the English language, thus the current research has also investigated the attitude towards blogging in ESL reading class in terms of gender.

Language learning is not only concerned with the intellectual capacity of the learner, but his attitude matters too. Attitude effects crucially on language learning as it decides the success and failure of language learning specifically in learning a second language [25]. Hence, effective English language learning is possible and successful when there is an active attitude [20].

Students and teachers are tied with each other because of teaching and learning; along with teacher and student, there are other factors too which influence students' attitudes of learning. There are many pieces of research conducted on the attitudes of learners in ESL class, one of the study conducted by [26] which revealed there are multiple factors which influence on students' attitude towards learning a language; as the environment, teachers' methodology, and the material used in the class. These study findings revealed learners were not much excited and enthusiastic about learning a language because of teachers' teaching style and another reason was the environment in the English classroom was not exciting enough to entice the students' motivation to learn the English language. Therefore, these factors are considered in the current research to integrate the technology into the ESL class to generate newness in English language learning.

The current generation is very much in touch with technology, as the new advancements are approaching, this motivation and interest are increasing more, and advancements can provide new ways of teaching and learning [27]. Hence, we must accept that change into our educational sector and must take advantage of that [28]. As time advances the way of teaching and learning has been advanced from teachercentered to learner-centered, teacher and learner are in search of innovation everywhere and in every way, but there is a dearth of innovation in Pakistani teaching, learning, and syllabi [28].

The technological era is advancing with innovative advancements, yet, the English teaching in Pakistan is deprived of technology integration. However, in many rural and urban areas teachers are still unaware of the technology usage in the class. The study conducted by [29] investigated that, most of the institutions in Pakistan even the audiovisual aids are not yet introduced. Flashcards, charts, pictures, models, films, scripts, tape recorders, computers, and overhead projectors, which facilitate English language learning and teaching; but Pakistan is lagging in it.

Another researcher [30] stated there is a dearth of ICT resources due to untrained staff and lack of cooperation of government due to the reasons there is less access to the resources and students are less interacting through ICT, the study further explained there is a need of integration of proper ICT tools into the education of Pakistan. Although students have not much access to technology into their educational context in Pakistan; but they use technology in their routine commonly as mobile phones, computers, and laptops, they are aware to use them.

A blog is a recent invention which is a very productive resource for students to practice and learn the English language outside and inside the classrooms. The first-ever blog emerged in 1994 with link.net. Since then the blogs and bloggers are expanded on a variety of topics and disciplines. Blogs provide meaningful opportunities for collaboration, content creation, facilitation of communication, and creating online community networks. According to [31], blogs are like personal diaries that are easy to develop and easy to use for reading and writing. They further stated, through blogging students learn from each other by 
knowing each other's ideas and feedbacks about particular learning, students can read and write according to their interests and wish within their own space, in comparison with the traditional classroom, blogging enhances students' interactions more and opens exciting horizons for learning the English language. According to [32], blogging is a good forum to discuss, read, reflect, and think critically. The discussion among peers by utilizing additional features of blogs like hyperlinks, images, videos, audio, e- documents enhance learners' reading skill.

Teachers are using blogs for multipurpose, as fetching material, sharing information, tracking students' progress, and engaging students into discussions on the material provided by teachers. Students also feel easy in blogging and learning while connected and with their teacher. Students do their group assignments and getting feedback on the course content and develop their language abilities easily by blogging [33]. Besides [34] expressed, blogs should be designed as they improve interaction and learning, as in virtual environments students have no time limitation they can better communicate with each other with continuous discussions. The enhancement in its popularity as an educational tool is because of its attributes provided to the educators because blogs are the easiest applications of social media with a low proficiency level of computer skill one can design and work on blogs [33-35]. Sawmiller [36] opined, blogging is serving all the learners with its multiple attributions of audio contents to support auditory learners, visual contents help those who love to learn by visuals, blogs' posts teach social learners, links to outside content to engage logical learners, a very secure environment for those who love to learn in a solitary environment, thus blogging help all types of learners to learn in an environment where they want to learn.

\section{RESEARCH METHOD}

This study aimed to investigate the significant difference among the engineering students' attitudes towards blogging in an ESL class in terms of gender and the relationship between the attitudes with learning English through blogging. The research method adopted in the present study relied on a qualitative approach to explore and develop knowledge on the detailed views about the experiences of the students who studied through blogging. To accomplish this, Engineering students from computer science engineering were taught English under blogging and were interviewed by using interview sampling to elicit their impression and individual opinion about blog usage. Meanings were discovered from their personal experiences and expressed insights and then reported and interpreted qualitatively.

\subsection{Sampling subject and size}

Convenient sampling was adopted in this study, this technique is used to identify and select students from first-year computer science engineering who are good at computer use, and the female students' number is also good there. As this study is qualitative, the sample size is small so that more in-depth data could be elicited from the participants. The six participants are in this study, comprising three males $(\mathrm{R} 1, \mathrm{R} 2$, and R 3 ) and three females (R 4, R 5, and R 6). The interviewees were from local public engineering university Mehran University of engineering and technology Jamshoro (MUET). The biographical data and specialties concerning gender were followed. Participants ranged in age from 18 to 20 years old. These students have been using the blog for learning English, such as Functional English subjects in the first year. The blog was designed and prepared by the researcher and it was used by one of the teachers from the same university to teach students reading skills for four weeks. The engineering university is provided with complete facilities of the educational environment. Thus, the campus has a language laboratory equipped with computers, wireless Internet access; comfortable and spacious lecture rooms as well as halls. The research was limited to six students from the first semester who participated in blog mediated class.

\subsection{Research instrument and procedures}

As this research is purely qualitative so, data required for analysis were acquired with the sampling instrument: A pre-designed interview to survey the students' personal experiences with blogging in English language education to know their attitude towards that blogging in ESL. A face-to-face mode of the interview was used to sample student's responses against in-depth and semi-structured interview questions developed earlier by the researcher. Semi-structured interviews are generally "organized around a set of predetermined open-ended questions, with other questions emerging from the dialogue between interviewer and interviewee(s)." Before running the interview session, the participants were initially informed about the purpose of the study and ensured the confidentiality of their identities. The participants were identified as R1, R2, R3, R4, R5, and R6 to keep their identities confidential. Besides, a Personal Data Form (PDF) was designed to collect basic demographic information about the participants and formulate a general idea about their backgrounds - interviewees' profile. 
Features of class instruction or characteristic used in the blog. The following items related to the mode of class instruction were characterized in the blogs: online reading texts; use of video materials e.g. YouTube; use of audio e.g. lectures, speeches, songs, music; use of pictures/photos, use of graphics; course schedule; class discussion or forum; comments/responses by instructors; comments/responses by students; link to the dictionary.

\subsection{Data management}

Interviewees' responses were tape-recorded and written in transcripts for preservation and analysis. Coding the data for each interviewed participant was applied, and based on the codes, thematic codes were drawn. The data of all participants were subject to scrutinizing and organization processes to find out commonalities and derive codes from such data. This exercise allowed for simple classification and categorization of interviews and blog observation data; thus, strengthening the qualitative analysis. According to [37], "qualitative data analysis primarily entails classifying things, persons, and events and the properties which characterize them."

\section{RESULTS AND DISCUSSION}

The data derived from interviews was gathered, systematized, managed, coded, and analyzed intending to seek replies to the pre-set research queries. An inductive approach of analysis was carried out on interview data to bring a more precise and existing picture of the existing issue. In doing so, responses and feedback of interviewees were assessed to discover the meaning-laden in individual blogging experiences and then interpreting these meanings scientifically in a linguistic education context. Supporting quotations from the participants were provided in the report to support the evaluation process. This exercise would add transparency and trustworthiness to data interpretation and validates the generated findings [38]. To test the honesty and accuracy of individual responses to interview questions, consistency checks were made on the interview transcripts - a procedure recommended by [39] in qualitative research.

The interviewed students reported that they were enjoying the blogging and reading due to the flexibility and multiple capabilities of the blog-reading texts including graphics, media materials used by students in their reading class benefited them to understand the texts.

The students were asked to comment on the exercises the used in the reading text on the blog so one of the students explained, his experience was great because of multimedia features he enjoyed doing those exercises and remained contented when he was doing the exercises because of the multimedia features the interest was continued.

In this respect, the $\mathrm{R} 1$ participant stated:

"I was very keen to use blogs as our reading resource because a blog is easy to use and manage. All the media features helped me a lot to understand the text. I used a dictionary while reading by just a click it was too easy to manage while reading online, I didn't feel to leave reading rather I continued with great curiosity to know more."

In this respect, the R4 participant stated:

"I had not much access with internet and computers before so, I am not good at computers yet, but I loved blogging I liked the online reading because it created ease for reading by attached videos, images, and audio."

In this respect, the $\mathrm{R} 2$ participant stated:

"The audio-visual aids enhanced my interest in learning reading especially, which I feel is a boring activity when I was watching images related to the texts it was clearing my concept more about the written matter."

Interviewed students were asked to read articles, participate in discussions, and commenting on posts in blogs, in this way they were automatically improving their level of English. Students were reported to acquire reading strategies.

One participant (R2) reported in his interview: 
"Before I had feeling reading is a boring activity but, I gradually felt I love reading once I finished one paragraph I wanted to read more and complete the text with great zeal, I feel I was fully involved into the matter provided to me because of the inference part of the text where we were given a video and through that we got to know what is next in the text which makes us curious to know about the text, I thoroughly enjoyed while I was blogging and reading."

One participant (R5) reported in her interview:

"I love to read books but now I love to read texts online, blogging is such a healthy activity which never gave me the impression I am getting bore rather I felt my self more involved in reading. How to read step by step was because of the exercises given; one part we were completing the other was approaching I learned a lot about reading."

Students were reading other students' comments, and therefore, they were learning from each other too. This was evident in the observation of R3 participant who reported that:

"I was reading my friends' comments, and sometimes I learned about the main idea of the text, about the exercises done by them, and I was trying to focus more."

One participant (R6) reported in her interview:

"I was not much into the discussion and comments sections due to reasons, but I was reading other students' comments and I was finding new ideas from them."

And that enhanced their positive attitude towards reading perfectly as they can take part in discussions easily and contribute their ideas about the texts they were reading through the blog.

The impression of R1 interviewee implied to a similar response:

"I found myself more confident while I was discussing with my fellows on the blog about the texts, we were reading that I learned how to read, by following the reading strategies taught by the teacher I knew everybody is reading so I became more conscious to read and involve in the discussion online."

One participant (R6) reported in her interview:

"I feel blogging is a good tool to use for language learning, social media sites somehow we are restrained to use but this is an educational blog I feel comfortable with this, and I feel confident and easy while blogging."

This attitude of knowledge acquisition and sharing helped students in gaining a better understanding of the reading texts. This was reported by the participants who, believe that the important aspect of blogging is driving students to focus on the knowledge laden in the information they encounter.

This stated by the participant R2:

"The main purpose of the blogging is to extend the learning process even outside of the classroom too so that there must be a continuous enrichment in our acquisition of knowledge about the texts of the reading. The blogging will lead us to understand the reading better and, therefore the learning objectives of the reading can be met."

Similarly, one participant (R5) reported in her interview:

"Sharing and connectivity are possible through blogging we are connected even out of the class which saves our time and our learning is continuous I used most of my time to attempt all the exercises to complete my tasks I thoroughly enjoyed while learning through blogging." 
Practicality in managing the reading tasks students felt easier and faster to deal with the learning process and materials on the blog. The interviewees experienced the positivity of blogs in managing the course materials, communication with students, and managing the discussions. The response of the R3 participant explained these aspects:

"Blog has become a good learning tool for me. It is very helpful and very practical. First, it provides me necessary information about class assignments and reading tasks. If I don't understand anything, I can write or ask in the comment box, I get answers to my questions, and I get connected with my teacher and fellows easily anytime. Secondly, when I am away, I can still manage my learning and communication with my teacher and fellows from a distance."

Improving students' digital literacy, it was observed that adopting a blog in teaching reading courses reflected positively in approaching the student to technology. By allowing students to interact with their teachers, peers, classmates, and information through blogs (i.e., online activities of reading tasks, participation in discussions, etc.), students gradually learn how to constructively apply the technology and appreciate its value and use in their life; thus, improving their ICT skills.

This was reported by R6 participant:

\begin{abstract}
"When I used it (blog), it was an application it was not a theory it was the hands-on experience and I see immediately how to use blogging in the reading classroom. I feel this integrated learning through blogging is actual learning towards the use of technology also because before I was not using blogging but now for learning it becomes meaningful for me."
\end{abstract}

In general, the participants had a positive attitude towards reading the blog and emphasized that the integration of blogs in teaching contributed successfully to the development of learning. From analyzing the interview responses of the sampled students, the positive aspects of embedding blogs in the class were reported to benefit each member of the learning process - the teacher and the student. All interviewed students expressed their satisfaction and confidence in the educational blog in achieving the desired learning objectives of their reading course because of its practicality and usefulness. Expressions extracted from the interview responses like the following all implied to the practicality and feasibility of the blog as a reliable tool for online education.

\title{
4.1. Results male and female engineering students' attitude regarding blogging in the reading class
}

As the current study explored male and female students' views regarding blogging in their reading ESL class, so their attitude is mainly positive towards blogging. There are very few differences pointed out from their attitude towards blogging. Those differences are mentioned in the Table 1.

Table 1. Male-female students' attitude differences

\begin{tabular}{ll}
\hline \multicolumn{1}{c}{ Male students } & \multicolumn{1}{c}{ Female students } \\
\hline I was very keen to use blogs as our reading resource. & I had not much access to the internet and computers before. \\
$\begin{array}{l}\text { I found myself more confident while I was discussing with } \\
\text { my fellows on the blog. }\end{array}$ & $\begin{array}{l}\text { I was not much into the discussion and comments sections } \\
\text { due to reasons. }\end{array}$ \\
$\begin{array}{ll}\text { I get connected with my teacher and fellows easily anytime. } \\
\text { The blog has become a good learning tool for me. }\end{array}$ & $\begin{array}{l}\text { Social media sites somehow, we are restrained to use. } \\
\text { Before I was not using blogging but now for learning it } \\
\text { becomes meaningful for me. }\end{array}$ \\
\hline
\end{tabular}

Table 1 shows the differences of male and female students attitude towards blogging, where female students are showing they were reluctant before to use blogging because of some reasons those reasons they have not shown but those can be social, educational or any pressure which gave them impression not to use social sites freely or maybe they were forbidden by parents or they may be away from the access of internet and computer there can be any reason but it shows previously before using this educational blog they were not comfortable with blogging but now they have changed their views and attitude. When they say, "I had not much access to the internet and computers before" when they do not have a positive attitude but when they have used it, they found it educational aid and their attitude to take blogging is an educational site an additional aid in learning so their attitude towards blogging seems positive. Male students are more confident, and they did not show any restricted idea or any emotion which shows that they were forbidden, or 
they were not using blogging before. Overall results are showing a very positive attitude of all students towards blogging to use that in the ESL classes in engineering universities.

The results affirm the statements with [31] that, blogs are like personal diaries that are easy to develop and easy to use for reading and writing. This is proven by the students' responses where they affirm that blogging is easy to do, maintain, and manage. Besides, they stated, blogging enhances students' interactions more and opens exciting horizons for learning the English language, this is also affirmed by the responses by the students, that they felt connected and they felt more excited.

Students do their group assignments and getting feedback on the course content and develop their language abilities easily by blogging [33]. In the current study results also show the same pieces of evidence that students were improving their reading attitude and learning through blogging. The answer to question two is obvious from students' responses that there is a positive effect of multimodal features of the blogging on the students' attitude towards blogging in the ESL class. Table 2 is showing those positive expressions of the students who were involved in the blogging and they experienced reading through blogging in ESL class. Those responses are mentioned in Table 2.

Table 2. The effect of multimodal features on students' attitude towards reading through blogging

\begin{tabular}{cl}
\hline S/No & \multicolumn{1}{c}{ Responses } \\
\hline 1 & $\begin{array}{l}\text { Easy to use and manage, media features helped me a lot to understand the text. I used a dictionary while } \\
\text { reading by just a click it was too easy to manage while reading online, I didn't feel to leave reading rather I } \\
\text { continued with great curiosity to know more." }\end{array}$ \\
2 & $\begin{array}{l}\text { I loved blogging I liked the online reading because it created ease for reading by attached videos, images, } \\
\text { and audio. }\end{array}$ \\
3 & $\begin{array}{l}\text { I feel I was fully involved in the matter provided to me because of the inference part of the text where we } \\
\text { were given a video. }\end{array}$ \\
4 & Audio-visual aids enhanced my interest in learning reading.
\end{tabular}

Table 2 is clearly showing that blogging and its multimodal features have a very positive effect on students' attitudes towards blogging in the ESL class. Students remarked that multimodal features helped them to improve reading and other skills with the help of videos, images, audios, and dictionary added ease to develop their language skills. These findings affirm the statements of [32] who say multimodal features help students in discussion and study. Respondents felt these multimodal features helped them to learn and motivated, excited, and enhanced their interest in learning the language. These findings are aligned with the opinion of [36] who opined these multimodal features enhanced students' learning in many ways.

\section{CONCLUSION}

Based on the findings of this study, it can be concluded that there are not many differences in the attitudes of girls and boys students of the engineering university of Sindh Pakistan towards blogging, although there are differences in many other contexts because of the gender bias society and gender bias educational system of Pakistan. This study revealed students either boys or girls are very much interested in technology use in the ESL classes like blogging, as the status of using blogs in Pakistani engineering universities for second language education is still in the initial stage. The surveyed students in this study who experienced blogs in language learning perceived blogs as a reliable and effective tool for developing the learning reading to Pakistani students. The endeavors of integrating blogs in language teaching received positive reflection from the surveyed students, they found blog-based education systems feasible, practical, and serving the student in achieving the desired objectives. Besides students want to use those multimodal features which only can be used through technology, not in books so, this type of learning with multimodal features improves their learning as well as motivation, and their positive attitude towards technology use like blogging. Besides online environment enhances students' confidence to read in peer and enjoy reading so, how blogging improves or not the collaborative learning and self-directed learning can be explored in different contexts by other researchers.

\section{REFERENCES}

[1] A. M. Sandhu, "Politics of Women's Education in Pakistan: An Analysis of Government Policies and their Implementation," Pakistan J. Hist. Cult., vol. 33, no. 1, pp. 113-136, 2012.

[2] P. Rajasekhar, C. N. Veena, and S. Kumar, "Gender differences in internet preferences and usage pattern among medical students," National Journal of Physiology Pharmacy and Pharmacology, vol. 8, no. 5, pp. 683-687, 2018.

[3] E. B. Weiser, "Gender differences in internet use patterns and internet application preferences: a two-sample comparison," CyberPsychology \& Behavior, vol. 3, no. 2, 2015. [Online]. Available: 10.1089/109493100316012 
[4] G. Ghiasi, V. Larivière, and C. R. Sugimoto, "On the compliance of women engineers with a gendered scientific system," PLoS One, vol. 10, no. 12, pp. 1-19, 2015.

[5] J. Howard, "Revisiting the Digital Divide(s): Technology-enhanced English Language Practices at a University in Pakistan," Australian Journal of Applied Linguistics, vol. 1, no. 2, pp. 64-86, 2018.

[6] J. Webster and R. Anderson, "Knowledge, access, and decision-making: Women's financial inclusion in Pakistan," Proceedings of the 1st ACM SIGCAS Conference on Computing and Sustainable Societies, pp. 1-12, 2018.

[7] G. Stoet and D. C. Geary, "The Gender-Equality Paradox in Science, Technology, Engineering, and Mathematics Education," Psychological Science, vol. 29, no. 4, pp. 581-593, 2018.

[8] N. J. Alzaidiyeen, "English as a Foreign Language Students Attitudes towards the Utilization of iPad in Language Learning," Malaysian Online Journal of Educational Technology, vol. 5, no. 3, pp. 16-24, 2017.

[9] M. Shahbaz, M. Islam, and M. A. Malik, "Role of Gender Differences and Parents' Education in Shaping L2 Motivation of Pakistani Students," Journal of Research and Reflections in Education, vol. 11, no. 2, pp. 210-223, 2017.

[10] S. Lee and D. Pulido, "The impact of topic interest, L2 proficiency, and gender on EFL incidental vocabulary acquisition through reading," Lang. Teach. Res., vol. 21, no. 1, pp. 118-135, 2017.

[11] M. Bouchefra and M. Baghoussi, "Algerian EFL University Teachers ' Attitudes towards Computer Assisted Language Learning: The Case of Djilali Liabes University," International Journal of Education and Literacy Studies, vol. 5, no. 2, pp. 132-139, 2017.

[12] R. Ellis, Understanding second language acquisition, 2nd edition. Oxford applied linguistics Press, Oxford university, 2015.

[13] H. Barki, "Measuring User Participation, User Involvement, and User Attitude Measuring user participation, user involvement, and user attitude," JSTOR, vol. 18, no. 1, pp. 59-82, 2014.

[14] J. Ardies, S. De Maeyer, D. Gijbels, and H. Van Keulen, "Students attitudes towards technology," International Journal of Technology and Design Education, vol. 25, no. 1, pp. 43-65, 2015.

[15] S. Jan, "Investigating the relationship between students' digital literacy and their attitude towards using ICT," International Journal of Educational Technology, vol. 5, no. 2, pp. 26-34, 2018.

[16] F. Pattanapichet, "Enhancement of performance and motivation through application of digital games," Teaching English with Technology, vol. 18, no. 1, pp. 77-92, 2018.

[17] M. Al-emran, H. M. Elsherif, and K. Shaalan, "Computers in Human Behavior Investigating attitudes towards the use of mobile learning in higher education," Computers in Human Behaviour, vol. 56, pp. 93-102, Mar. 2016.

[18] M. Y. Al-shawesh and S. Hussin, "The Effect of the CAREY Program on the Students ' Reading Attitude towards Reading English Materials,” English Language Teaching, vol. 8, no. 12, pp. 98-111, 2015.

[19] F. Al-kathiri, "Beyond the Classroom Walls : Edmodo in Saudi Secondary School EFL Instruction , Attitudes and Challenges," English Language Teaching, vol. 8, no. 1, pp. 189-204, 2015.

[20] L. Lin, "Impacts of the Problem-based Learning Pedagogy on English Learners' Reading Comprehension, Strategy Use , and Active Learning Attitudes," Journal of Education and Training Studies, vol. 5, no. 6, pp. 109-125, 2017.

[21] S. Chotitham and S. Wongwanich, "The Reading Attitude Measurement for Enhancing Elementary School Students' Achievement," Procedia - Soc. Behav. Sci., vol. 116, pp. 3213-3217, 2014.

[22] D. Kulaç and J. Walters, "The Effect of Contextual Inferencing Strategies on EFL Learners' Attitudes towards Reading," Procedia - Soc. Behav. Sci., vol. 232, no. April, pp. 486-493, 2016.

[23] W. Grabe and F. L. Stoller, Teaching and researching reading, 2nd Edition. New York, USA: Routledge, 2002.

[24] A. Morni and S. Sahari, "The Impact of Living Environment on Reading Attitudes," Procedia - Soc. Behav. Sci., vol. 101, pp. 415-425, 2013.

[25] G. T. Safotso and N. Tompte, "Attitudes and Motivation of Chadian Learners of English," World J. Educ., vol. 8, no. 2, pp. 174-180, 2018.

[26] F. Zulkefly, "Malaysian Rural Secondary School Students' Attitudes towards Learning English as a Second Language," International Journal of Instruction, vol. 12, no. 1, pp. 1141-1156, 2019.

[27] Y. Shaw, "At the crossroads of learning and culture: Identifying a construct for effective Computer-Assisted Language Learning for English language learners," ProQuest Diss. Theses, pp. 197-n/a, 2010. [Online]. Available: http://search.proquest.com/docview/305227873?accountid=11262LA-English

[28] A. Gilakjani and N. Sabouri, "A Detailed Analysis over Iranian EFL Teachers' Beliefs towards Using Pronunciation Software in Teaching English Pronunciation," International Journal of Applied Linguistics and English Literature, vol. 6, no. 7, pp. 227-235, 2017.

[29] M. Yasin, S. Mehmood, G. Fareed, and M. U1 Hassan, "Perceptions of the Teachers and the Students toward Using Multimedia as an Effective Tool for Teaching and Learning English in Pakistan," Bulletin of Business and Economics, vol. 3, no. 4, pp. 176-181, 2014.

[30] M. Saleem, "Effects of ICT on Student's Learning at Secondary Level in Private Schools of the Punjab," International Journal of Distance Education and E- Learning, vol. 3, no. 1, pp. 69-89, 2017.

[31] J. Merelo-Guervós, et al., "Clustering web-based communities using self-organizing maps," In IADIS International Conference Web Based Communities, pp. 158-165, 2004.

[32] L. C. Larson, "Reader Response Meets New Literacies : Empowering Readers in Online Learning Communities," The Reading Teacher, vol. 62, no. 8, pp. 638-648, 2009.

[33] C. L. Al-qallaf and A. S. R. Al-mutairi, "Digital literacy and digital content supports learning: The impact of blogs on teaching English as a foreign language," The Electronic Library, vol. 34, no. 3, pp. 522-547, 2016. 
[34] S. Hussin, R. O. S. Aboswide, N. Ismail, and S. Kum Yoke, "Exploring Instructors' Rationale and Perspectives in Using Blogs as a Tool for Teaching English as a Second Language," English Language Teaching, vol. 9, no. 10, pp. 142-155, 2016.

[35] Y. H. Z. Hong, "The effects of a flipped English classroom intervention on students' information and communication technology," Educ. Technol. Res. Dev., vol. 64, no. 2, pp. 175-193, 2016.

[36] A. Sawmiller, "Classroom Blogging: What is the Role in Science Learning ?" The Clearing House: A Journal of Educational Strategies, Issues and Ideas, vol. 83, no .2, pp. 44-48, 2010.

[37] N. V. Ivankova, J. W. Creswell, and S. L. Stick, "Using Mixed-Methods Sequential Explanatory Design: From Theory to Practice," Field Methods, vol. 18, no. 1, pp. 3-20, 2006.

[38] A. Tong, P. Sainsbury, and J. Craig, "Consolidated criteria for reporting qualitative research (COREQ): A 32-item checklist for interviews and focus groups," Int. J. Qual. Heal. Care, vol. 19, no. 6, pp. 349-357, 2007.

[39] J. W. Creswell and V. L. P. Clark, Mixed methods desigming and conducting. Sage Publications, 2017. 